\title{
Concurrent Chemoradiotherapy Using Cisplatin, Tegafur, and Leucovorin for Advanced Squamous Cell Carcinoma of the Hypopharynx and Oropharynx
}

\author{
Hung-Ming Wang ${ }^{1}$, Cheng-Lung Hsu ${ }^{1}$, Chia-Hsun Hsieh ${ }^{1}$, Kang-Hsing Fan ${ }^{2}$, Chien-Yu Lin ${ }^{2}$, \\ Joseph Tung-Chieh Chang ${ }^{2}$, Shiang-Fu Huang ${ }^{3}$, I-How Chen ${ }^{3}$, Chun-Ta Liao ${ }^{3}$, Shu-Kung Ng ${ }^{4}$
}

Background: To evaluate the efficacy and adverse events of cisplatin, tegafur, and leucovorin concomitantly with radiotherapy for patients with advanced, non-metastatic squamous cell carcinoma (SCC) of the oropharynx and hypopharynx.

Methods: The PTL regimen consisted of cisplatin (P) $50 \mathrm{mg} / \mathrm{m}^{2}$ on day 1 , oral tegafur (T) $800 \mathrm{mg} /$ day plus leucovorin (LV) $60 \mathrm{mg} /$ day on days 1 through 14 . It was repeated every 2 weeks through the radiotherapy course. Conventional radiotherapy with 1.8-2.0 Gy/day, 5 days per week, was delivered in a total dose of between 70 and $72 \mathrm{~Gy}$.

Results: $\quad$ Sixty-five patients with stage III or IV of SCC of the head and neck were consecutively treated between May 2002 and November 2005. Forty-six (70.7\%) patients had complete response after concomitant chemoradiotherapy (CCRT). With a median follow-up of 54.0 months (range 1-103 months), the 5-year locoregional control, progression-free survival, and overall survival rates were $50.6 \%, 40.7 \%$, and $59.7 \%$, respectively. Three $(4.6 \%)$ patients had toxic death during treatment.

\section{At a Glance Commentary}

Scientific background of the subject

Updated meta-analysis shows that concomitant chemoradiotherapy (CCRT) is the standard treatment for SCCHN for intent of organ preservation and for unresectable diseases. However, studies investigated a variety of agents and schedule, and the optimum regimen is yet to be defined.

\section{What this study adds to the field}

The current study demonstrated that biweekly chemotherapy regimen of cisplatin/tegafur/leucovorin can be incorporated into radiotherapy for advanced sqaumous cell carcinoma of oropharynx and hypopharynx with comparative efficacy and acceptable adverse events.

Fifty-one (80.0\%) patients experienced grade 3-4 mucositis which occurred in about $35 \%$ of the CCRT duration. The functional preservation rate among post-CCRT complete responders was 93.5\% (43/46). The median cisplatin accumulated dosage was $150 \mathrm{mg}$, and the rate of hearing impairment among the survivors was $7.8 \%$.

Conclusion: CCRT with outpatient-based PTL for advanced SCC of oropharynx and hypopharynx is feasible and has comparative efficacy and acceptable adverse events.

(Biomed J 2014;37:133-140)

Key words: chemoradiotherapy, chemotherapy, head and neck cancer, leucoverin, radiotherapy, tegafur

$\mathrm{C}$ Tombining chemotherapy and radiation therapy for patients with local advanced squamous cell carcinoma of the head and neck (SCCHN) has been extensively explored in the past decades. Several phase III trials and meta-analyses

From the ${ }^{1}$ Division of Medical Oncology, Department of Internal Medicine, Chang Gung Memorial Hospital at Linkou, Chang Gung University College of Medicine, Taoyuan, Taiwan; ${ }^{2}$ Department of Radiation Oncology, Chang Gung Memorial Hospital at Linkou, Chang Gung University College of Medicine, Taoyuan, Taiwan; ${ }^{3}$ Section of Head and Neck Surgery, Department of Otorhinolaryngology, Chang Gung Memorial Hospital at Linkou, Chang Gung University College of Medicine, Taoyuan, Taiwan; ${ }^{4}$ Department of Diagnostic Radiology, Chang Gung Memorial Hospital at Linkou, Chang Gung University College of Medicine, Taoyuan, Taiwan

Received: Mar. 23, 2013; Accepted: Jun. 19, 2013

Correspondence to: Dr. Hung-Ming Wang, Division of Medical Oncology, Department of Internal Medicine, Chang Gung Memorial Hospital at Linkou. 5 Fusing St., Gueishan, Taoyuan 333, Taiwan, (R.O.C.) Tel.: 886-3-3281200 ext. 8820; Fax: 886-3-3278211; E-mail:whm526@adm.cgmh.org.tw

DOI: $10.4103 / 2319-4170.117893$ 
now allow us to make evidence-based recommendations that concomitant chemoradiotherapy (CCRT) may be the best way to incorporate chemotherapy into radiotherapy for treating patients with SCCHN. ${ }^{[1-6]}$

Cisplatin plus 5-flurouracil (5-FU) is still commonly used as induction chemotherapy or during CCRT for SCCHN. ${ }^{[7-10]}$ The literature reports suggested that optimal scheduling of 5-FU as a radiosensitizer is strongly dependent on continuous exposure of tumor cells to 5-FU during irradiation for at least 8 hours. ${ }^{[11-13]}$ Because of the short half-life of 5-FU, it must be administered as a continuous infusion to achieve prolonged tumor cell exposure at effective 5-FU levels. However, the continuous 5-FU infusion is limited in its need for an indwelling venous catheter and a portable infusion pump.

Eighty to ninety percent of SCCHN patients in Taiwan were betel quid chewers; $30-40 \%$ of them experienced mucositis World Health Organization (WHO) grade 3 from cisplatin/5-FU in a neoadjuvant chemotherapy setting. This was much higher than the $8-11 \%$ reported in Western populations and was related to oral submucous fibrosis from betel quid chewing. ${ }^{[14,15]}$ To improve our patients' compliance to cisplatin/5-FU-based chemotherapy, we have demonstrated that outpatient-based cisplatin/oral 5-FU prodrugs/ leucovorin (LV) combined regimens are of low toxicity and comparative efficacy to cisplatin/5-FU. ${ }^{[16,17]}$ The oral 5-FU prodrugs also provide a substantial improvement in the ease of administration of 5-FU as a radiosensitizer. The aforementioned served as our rationale for using cisplatin/ oral 5-FU prodrugs/LV for SCC of oropharynx and hypopharynx (SCCOH) treated primarily by CCRT. Here, we report our experience of routine practice using cisplatin/oral 5-FU prodrugs/LV in a prospectively assembled cohort comprising patients with SCCOH treated with CCRT between 2002 and 2005. This analysis was approved by institutional research ethics board.

\section{METHODS}

\section{Eligibility criteria}

The patients fulfilled the following criteria: Newly diagnosed, previously untreated SCCOH; stage III or IV disease; without distant metastasis; measurable disease documented by a computed tomography (CT) scan or magnetic resonance imaging (MRI); and a WHO performance status $\leq 2$. They had an adequate bone marrow reserve (leukocyte count $\geq 4000 / 1$ and platelets $\geq 100,000 / 1$ ), adequate renal function (serum creatinine $<2.0 \mathrm{mg} / \mathrm{dl}$ ), and adequate liver function [total bilirubin $\leq 1.5 \times$ upper limit of normal (ULN), serum glutamate oxaloacetate transaminase (SGOT), and serum glutamate pyruvate transaminase $(\mathrm{SGPT}) \leq 2.5 \times \mathrm{ULN}]$. Patients with serious concomitant illness, for example, liver cirrhosis, angina, or myocardial disease, uncontrolled infection, or intestinal obstruction, malabsorption or any other condition that restricted the intake of oral medication, were ineligible. However, patients who were fed through nasogastric tubes or gastrostomy tubes without intestinal malabsorption or obstruction were eligible.

Pretreatment evaluation consisted of a history and physical examination, flexible fiber-optic equipment, measurement of all detectable tumors, chest X-rays, CT scan or MRI of the head and neck, bone scan, and liver echogram. Patients were staged in accordance with the 2002 American Joint Committee on Cancer staging system. All patients signed an informed consent before treatment.

\section{Treatment plan}

The chemotherapy regimen consisted of cisplatin (P) $50 \mathrm{mg} / \mathrm{m}^{2}$ administered by continuous intravenous (IV) infusion for $3 \mathrm{~h}$ on day 1, oral tegafur (T) $800 \mathrm{mg} /$ day on days 1 through 14, and oral leucovorin (L) $60 \mathrm{mg}$ /day on days 1 through 14. This PTL regimen was delivered at outpatient clinics every 14 days. Tegafur was supplied as a 200-mg capsule and leucovorin as a 15-mg tablet. Both were administered concurrently in four dividing doses. Tegafur and leucovorin were powdered for tube-feeding patients. All patients received IV antiemetics of serotonin receptor (5-HT3) antagonists before cisplatin. Dexamethasone $2 \mathrm{mg}$ daily for 7 days and metoclopramide $30 \mathrm{mg}$ daily for 14 days were used to mitigate nausea and delayed emesis that would affect the compliance of oral medication. If there was $\geq$ grade 2 vomiting in the first cycle, oral 5-HT3 antagonists were prescribed for 5 more days after cisplatin in the next cycles. Compliance of oral tegafur was determined by patient reporting.

In all cases, radiotherapy was administered using 6-MV photon beams for 2 Gy per fraction, every fraction per day and 5 days a week. The radiotherapy area included gross tumor area with at least $1 \mathrm{~cm}$ margins and whole neck for $46 \mathrm{~Gy}$, then cone-down boost to the initial gross tumor area with close margins to 72 Gy. Intensity-modulated radiotherapy (IMRT) was used in all patients.

\section{Evaluation of adverse events and response}

Adverse events were assessed according to the National Cancer Institute (NCI) Common Toxicity Criteria (CTC) version 2.0 and Radiation Therapy Oncology Group (RTOG) toxicity scoring system. Patients were assessed weekly for acute adverse events during CCRT. Tube feeding through nasogastric or percutaneous gastrostomic route was done as needed for ensuring adequate nutrition and compliance of oral medication.

For $\geq$ grade 2 neutropenia, thrombocytopenia, or liver dysfunction, the chemotherapy had to be withheld. 
Chemotherapy was restarted without dose modification when the adverse event resolved to $<$ grade 2 . If febrile neurtopenia or thrombocytopenia with $>12$ unit platelet transfusion was needed, the dose of tegafur was reduced by $200 \mathrm{mg} /$ day when chemotherapy was restarted. Cisplatin was withheld when serum creatinine $\geq 2.0 \mathrm{mg} / \mathrm{dl}$; patients were then treated with tegafur plus leucovorin only. For grade 4 radiation-related mucositis or dermatitis and grade 3 diarrhea, chemotherapy was withheld and restarted with a dose reduction of $200 \mathrm{mg}$ tegafur per day when the adverse events resolved to $\leq$ grade 3 mucositis or dermatitis or $\leq$ grade 2 diarrhea. When a dose reduction was required, no dose re-escalation was performed subsequently. If $>2$ times of dose modifications were needed, the patient had to be taken off the study. Radiotherapy was withheld for grade 4 radiation-related mucositis or dermatitis, or uncontrolled infection. It was restarted when the adverse events resolved to $\leq$ grade 3 mucositis or dermatitis, and with no uncontrolled infection.

Response analysis was determined between 8 and 12 weeks after completion of definitive CCRT. A biopsy was performed if there were any clinical suspicions of a residual tumor. Patients were not routinely biopsied to confirm the absence of tumors. A complete response required the disappearance of all clinical, radiographic, and, if applicable, pathologic evidences of disease. Any pathologically confirmed residual disease would result in appropriate surgical resection. Neck dissection was not recommended for patients with N2-3 disease who achieved complete response after CCRT in both primary and neck lymph nodes. Salvage surgery was recommended, if appropriate, for local or regional disease recurrence.

Patients were followed up by the multidisciplinary team after completion of therapy every 2-3 months. Chest X-rays were obtained yearly, and other radiographic studies were performed as clinically indicated.

\section{Statistical analysis}

The time-to-event end points analyzed were overall survival (OS), progression-free survival (PFS), and locoregional control (LRC). The compliance to treatment, treatment-related adverse events, and the functional preservation status were also analyzed.

OS was defined as the time from treatment to death resulting from any cause. PFS was defined as the time from treatment until disease progression or relapse, or secondary primary, or death from any cause. LRC was defined as the time from treatment to failure of disease control above clavicle. Survival estimations were performed using the method of Kaplan-Meier. The logrank test was used for univariate analysis and the Cox proportional hazards model was used for multivariate analysis. All statistical computations were performed with the statistical software SPSS 12.0 (SPSS Inc., Chicago, IL, USA).

\section{RESULTS}

Between May 2002 and November 2005, a total of 65 consecutive patients who fulfilled the eligible criteria were recruited. The data were prospectively collected but retrospectively analyzed. The characteristics of the population are listed in Table 1, and the stages of tumor and lymph node are listed in Table 2. Stage III was found in $18(26.2 \%)$ patients and stage IV in 47 (73.8\%) patients.

\section{Adverse events}

The common acute adverse events are summarized in Table 3. The most common grade 3-4 adverse event was mucositis. Forty-seven patients $(73.8 \%)$ experienced grade 3 mucositis and $4(6.2 \%)$ patients experienced grade 4 mucositis. Two patients $(3.1 \%)$ had grade 4 vomiting and 1 patient (1.5\%) had grade 4 dermatitis. Grade 3-4 mucositis occurred in about $35 \%$ of the entire CCRT duration. Three patients $(4.6 \%)$ died during CCRT as toxic death.

Table 1: Patient characteristics

\begin{tabular}{llc}
\hline Characteristics & & Number $(\%)$ \\
\hline Gender & Male/Female & $63 / 2$ \\
Age & Median (range) & $52(37-76)$ \\
Performance status & 0 & $30(46.1)$ \\
& 1 & $33(50.8)$ \\
Site & 2 & $2(3.1)$ \\
& Oropharynx & $35(53.8)$ \\
& Tonsil & $25(38.5)$ \\
& Tongue base & $9(13.8)$ \\
& Soft palate & $1(1.5)$ \\
Differentiation & Hypopharynx & $30(46.2)$ \\
& Well & $4(6.2)$ \\
& Moderate & $34(52.3)$ \\
Stage & Poor & $11(16.9)$ \\
& No description & $16(24.6)$ \\
& III & $17(26.2)$ \\
Resectability & IVa & $34(52.3)$ \\
& IVb & $14(21.5)$ \\
& Resectable & $48(73.8)$ \\
& Unresectable & $17(26.2)$ \\
\hline
\end{tabular}

Table 2: Tumor-node staging

\begin{tabular}{lccccccc}
\hline Tumor/node & 0 & 1 & $2 \mathrm{~A}$ & $2 \mathrm{~B}$ & $2 \mathrm{C}$ & 3 & Total \\
\hline 1 & 0 & 0 & 1 & 1 & 0 & 1 & 3 \\
2 & 0 & 3 & 3 & 3 & 0 & 1 & 10 \\
3 & 10 & 5 & 2 & 2 & 3 & 0 & 22 \\
$4 \mathrm{~A}$ & 7 & 3 & 2 & 2 & 3 & 2 & 19 \\
$4 \mathrm{~B}$ & 1 & 2 & 0 & 2 & 4 & 2 & 11 \\
Total & 18 & 13 & 8 & 10 & 10 & 6 & 65
\end{tabular}

Stage III: $26.2 \%$; stage IV: $73.8 \%$ (stage IVb: $21.5 \%$ ) 


\section{Compliance}

Thirty-one patients had received PTL chemotherapy before radiotherapy started. Twenty-two patients received one cycle, and nine patients received two cycles of PTL. One patient received only one cycle of chemotherapy and decided to undergo operation. The chemotherapy cycles delivered during the whole treatment course ranged from one to five, with a median of three cycles. Thirty patients $(46.2 \%)$ received more than four cycles of PTL. The median cisplatin dosage was $75 \%$ (range $25-100 \%$ ) of the scheduled dose and that of tegafur was $77.5 \%$ (range $17-100 \%$ ). The median radiotherapy duration was 57 days (range 17-99 days) and median radiotherapy dosage was 7200 cGy (range 24007800 cGy). Five patients (7.7\%) received a radiation dosage $<6000 \mathrm{cGy}$, which was given due to toxic death in three patients, intercurrent disease in one patient, and intolerance in one patient. Twenty-one patients needed hospitalization due to treatment-related side effects: infection in 12 patients, diarrhea in 1 patient, vomiting in 1 patient, and percutaneous gastrostomy feeding tube placement in 7 patients. Sixty-one patients $(93.8 \%)$ experienced body weight loss, and $34(52.3 \%)$ patients needed tube feeding during treatment. The compliance of treatment is summarized in Table 4 .

\section{Therapeutic results}

The efficacy data were reported using the intent-to-treat patient population. After completion of CCRT with PTL regimen, $46(70.7 \%)$ patients had complete response, 13 (20.0\%) patients had partial response or stable disease, and 1 patient had progressive disease. Nine patients without complete response underwent operation for residual disease. Overall, 55 (84.6\%) patients became disease-free after the CCRT with or without salvage surgery for residual disease.

The median follow-up period was 54.0 months (range 1-103 months). The 5-year LRC, PFS, and OS rates were $50.6 \%, 40.7 \%$, and $59.7 \%$, respectively [Figures 1-3]. The 5 -year OS rates of post-CCRT complete responders and post-operation complete responders were $74.9 \%$ and $44.4 \%$, respectively (logrank test $p=0.019$ ). Of the 46 patients who had complete response after CCRT, $6(13.0 \%)$ patients developed local recurrence, $2(4.3 \%)$ patients had distant metastasis, $12(26.1 \%)$ patients developed second primary cancer, $1(2.1 \%)$ patient had local recurrence and second primary cancer, and $1(2.1 \%)$ patient had distant metastasis and second primary cancer. Thirty-four patients (73.9\%) were alive at the last follow-up (30 patients were cancer-free, 1 patient had hepatocellular carcinoma (HCC), and 3 patients had recurrent SCCHN). Of the nine patients who received an operation for post-CCRT residual disease, 4 (44.4\%) experienced local recurrence, $1(11.1 \%)$ developed second primary cancer, $1(11.1 \%)$ had distant metastasis, and $3(33.4 \%)$ patients were alive without disease. Totally, 33 (50.8\%) patients were alive without disease, $1(1.5 \%)$ patient was alive with HCC, and 4 (6.2\%) patients had cancer recurrence, but were lost to follow-up. There were 27 (41.5\%) patients who died either during or after treatment. Among these, $3(4.6 \%)$ patients died during treatment, $2(3.0 \%)$ patients died of intercurrent disease, $12(18.4 \%)$ patients died of cancer recurrence or progression, and $10(15.4 \%)$ patients died of second primary cancer.

The sites of 15 patients with second primary cancer were: Oral cavity 3 , oropharynx 2 (1 patient had hypopharyngeal cancer first and developed tongue base cancer later and the other had left tonsil cancer first and developed right tonsil cancer 3 years later), hypopharynx 1 (this patient had tonsil cancer first), esophagus 3 , lung 4 , liver 1 , and acute leukemia 1 . The median time to develop second primary cancer was 36.0 months (range 5-62 months).

Regarding chronic adverse events, one patient who had received neck dissection had grade 3 neck fibrosis. Out of 46 post-CCRT complete responders, 2 patients had permanent tracheostomy (one due to adverse event of CCRT and the other one due to treatment for second primary) and

Table 3: Adverse events (according to NCI CTC version 2.0)

\begin{tabular}{|c|c|c|c|c|c|c|c|c|c|c|}
\hline \multirow{2}{*}{$\begin{array}{l}\text { CTC grading } \\
\text { Adverse event }\end{array}$} & \multicolumn{5}{|c|}{$\%$ of CCRT duration } & \multicolumn{5}{|c|}{$\%$ of patients } \\
\hline & 0 & 1 & 2 & 3 & 4 & 0 & 1 & 2 & 3 & $\overline{4}$ \\
\hline Neutropenia & 87.1 & 7.0 & 5.1 & 0.8 & & 50.0 & 23.4 & 21.9 & 4.7 & \\
\hline Anemia & 17.3 & 66.8 & 15.1 & 0.8 & & 1.6 & 64.1 & 31.3 & 3.1 & \\
\hline Thrombocytc & 72.8 & 24.9 & 2.3 & & & 42.2 & 45.3 & 12.5 & & \\
\hline Vomiting & 80.1 & 11.2 & 7.2 & 1.0 & 0.5 & 50.8 & 13.8 & 26.2 & 6.2 & 3.1 \\
\hline Mucositis & 6.7 & 12.9 & 44.9 & 34.5 & 1.0 & 3.1 & 1.5 & 15.4 & 73.8 & 6.2 \\
\hline Dermatitis & 24.3 & 38.9 & 33.4 & 3.0 & 0.4 & 7.7 & 15.4 & 66.2 & 9.2 & 1.5 \\
\hline Diarrhea & 94.5 & 2.7 & 2.2 & 0.6 & & 75.0 & 10.9 & 10.9 & 3.1 & \\
\hline Renal dysfunction & 96.7 & 2.8 & 0.5 & & & 89.1 & 7.8 & 3.1 & & \\
\hline Liver dysfunction & 96.4 & 3.6 & & & & 90.6 & 9.4 & & & \\
\hline
\end{tabular}

Abbreviation: NCI CTC: National cancer institute, Common toxicity criteria

Table 4: Compliance to therapy

\begin{tabular}{ll}
\hline Chemotherapy administration & \\
Cycles [median (range)] & $3(1-5)$ \\
1/2/3/>=4 & $6.2 / 12.3 / 35.3 / 46.2(\%)$ \\
Dosage [median (range)] & \\
Cisplatin & $75 \%(25-100 \%)$ \\
Oral 5-FU & $77.5 \%(17-100 \%)$ \\
Body weight loss [mean (range)] & $8.3 \%(1-23 \%)^{*}$ \\
Hospitalization & $21(32.8 \%) \dagger$ \\
Tube feeding & $34(53.1 \%) \ddagger$ \\
Radiotherapy & \\
Duration [median (range)] & $57(17-99)$ days \\
Dosage $<6000 \mathrm{cGy}$ & 5 patients \\
\hline
\end{tabular}

*: 61 patients (93.8\%) had body weight loss; ${ }^{\dagger}$ : Causes of admission: infection 12 , diarrhea 1 , vomiting 1 , for percutaneous gastrostomy creation 7 ; : Percutaneous gastrostomy tube $24(37.2 \%)$, nasogastric tube $10(15.6 \%)$ 


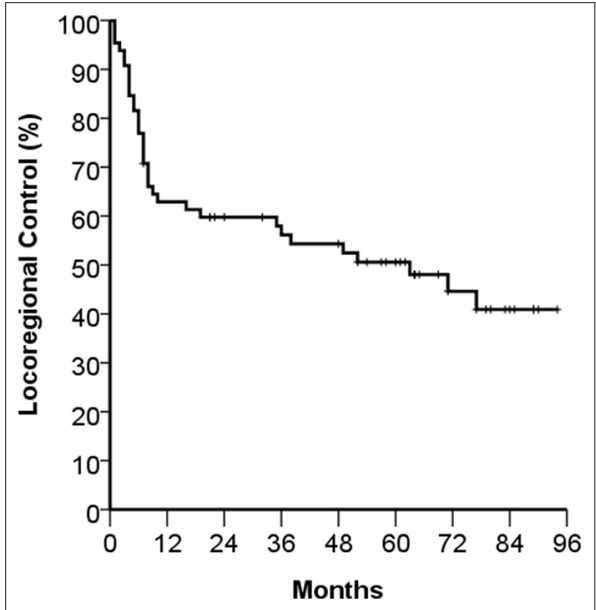

Figure 1: Locoregional control rate

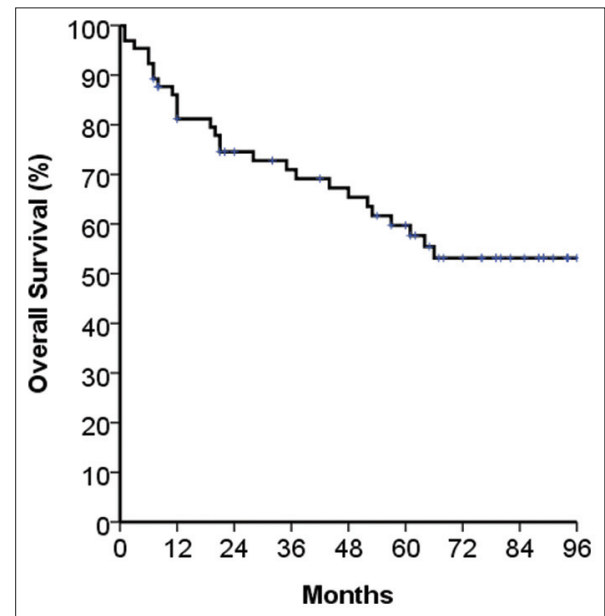

Figure 2: Progression-free survival rate

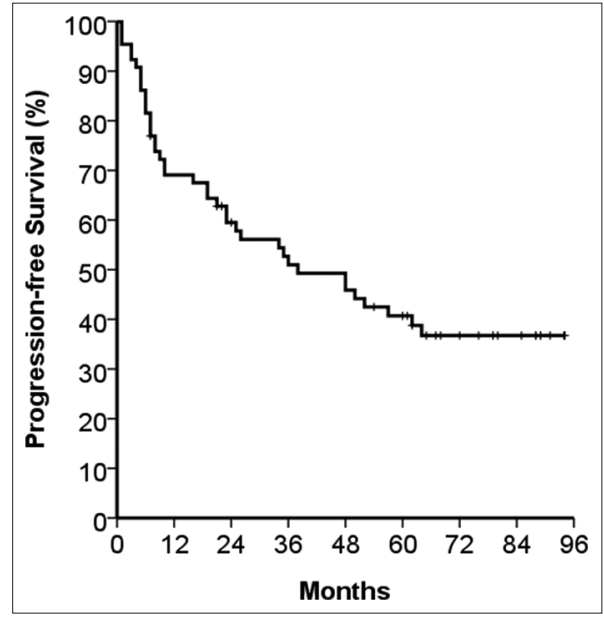

Figure 3: Overall survival rate

7 patients were on paste or liquid diet ( 3 were CCRT related, 2 due to operation for local recurrence, 1 due to treatment for second primary, and 1 due to stroke related dysphagia). The tracheostomy-free and tube-feeding free rate among
post-CCRT complete responders was 93.5\% (43/46). Three patients had strokes during follow-up. The ages of the patients who suffered strokes were 61,68 , and 74 years. The periods between completion of CCRT and occurrence of strokes were 12, 56, and 32 months, respectively. Additionally, there were 3 patients out of 38 (7.8\%) who had hearing impairment that influenced their daily lives.

\section{DISCUSSION}

According to the large meta-analyses conducted based on individual patient data of randomized trials, CCRT is the standard treatment for locally advanced SCCHN..$^{[5,18]}$ CCRT conferred an absolute survival benefit of $8.6 \%$ at 5 years for cancer-related death. The survival benefit mostly comes from decreasing local failure (9.3\% at 5 years) rather than distant failure (2.5\% at 5 years). Regarding the optimal chemotherapy regimen, according to the meta-analyses, cisplatin alone, or cisplatin or carboplatin associated with 5-FU provided similar benefit. ${ }^{[18]}$

The optimal dose of cisplatin administration during CCRT is still controversial. Many studies use cisplatin $100 \mathrm{mg} / \mathrm{m}^{2}$ bolus dosing on days 1,22 , and 43 of radiotherapy. However, compliance is a problem with the three-cycle high-dose cisplatin. Nearly one-third of patients do not complete all cycles, and subset analyses suggested that two cycles with a total of $200 \mathrm{mg} / \mathrm{m}^{2}$ cisplatin are as effective as three cycles. ${ }^{[1,3,4]}$ Lower doses of CDDP, for example, $30-40 \mathrm{mg} / \mathrm{m}^{2}$ weekly, are also commonly used. However, there is no direct comparison between weekly low-dose CDDP and 3-week high-dose CDDP. Our PTL regimen used cisplatin $50 \mathrm{mg} / \mathrm{m}^{2}$ biweekly with a plan to administer $200 \mathrm{mg} / \mathrm{m}^{2}$ cisplatin during CCRT, and achieved a median dosage of received was $150 \mathrm{mg} / \mathrm{m}^{2}$.

The complete response rate of primary CCRT in our study was $70.7 \%$. The 5-year LRC, PFS, and OS rates of our study were $50.6 \%, 40.7 \%$, and $59.7 \%$, respectively. The reported 5-year LRC and OS rates in studies using comparable CCRT, as reported in the literature, range from 47 to $77 \%$ and from 22 to $50 \%$, respectively. ${ }^{[2,19-23]}$ In the updated analyses of Meta-analysis of Chemotherapy in Head and Neck Cancer (MACH-NC), ${ }^{[18]}$ the 5-year overall survival for CCRT was $33.7 \%$, with an absolute benefit of $6.5 \%$ at 5 years than just RT alone. The lower-dose CDDP regimen we used could achieve comparable results to those obtained with a higher cisplatin dose.

Our report included patients of SCCHN arising from oropharynx and hypopharynx, and their 5-year overall survival was $53 \%$ for oropharynx and $67 \%$ for hypopharynx $(p=0.681)$. The median survival was 65.6 months (95\% confidence interval, 51.3-80.0 months) and 65.9 months (95\% confidence interval, 53.3-78.5 months) for oropharynx and hypopharynx, respectively. In Taiwan, 
Table 5: Trials of concurrent chemoradiotherapy with platinum plus oral 5-FU prodrugs for head and neck cancer

\begin{tabular}{|c|c|c|c|c|c|c|c|}
\hline Authors & $N$ & Radiotherapy, Gy & Chemotherapy & $\begin{array}{l}\text { Complete } \\
\text { response, \% }\end{array}$ & $\begin{array}{l}\text { Locoregional } \\
\text { control }\end{array}$ & $\begin{array}{l}\text { Overall } \\
\text { survival }\end{array}$ & $\begin{array}{l}\geq \mathrm{Gr} 3 \\
\text { mucositis, \% }\end{array}$ \\
\hline Segura, 2005 & 58 & $65-70$ & $\begin{array}{l}\text { Carboplatin } 100 \mathrm{mg} / \mathrm{m}^{2} / \text { week } \\
\text { UFT } 400 \mathrm{mg} / \text { day }\end{array}$ & 41.0 & $\begin{array}{l}10 \text { months } \\
\text { (median) }\end{array}$ & $\begin{array}{l}18.4 \text { months } \\
\text { (median) }\end{array}$ & 47.0 \\
\hline Kim, 2005 & 37 & $70-70.2$ & $\begin{array}{l}\text { Cisplatin } 80 \mathrm{mg} / \mathrm{m}^{2} \text { on day } 1 \text {, } \\
\text { capecitabine } 825 \mathrm{mg} / \mathrm{m}^{2} \text { bid on day } \\
1-14 \text {; every } 3 \text { weeks a cycle, for two } \\
\text { cycles }\end{array}$ & 78.4 & $72.6 \%$ (2-year) & $76.8 \%$ (2-year) & 67.6 \\
\hline Fesneau, 2010 & 72 & 70 & $\begin{array}{l}\text { Carboplatin } 70 \mathrm{mg} / \mathrm{m}^{2} / \text { day on day } 1-4 \text {, } \\
\text { every } 21 \text { days a cycle, for three cycles; } \\
\text { UFT } 300 \mathrm{mg} / \mathrm{m}^{2} / \text { day+LV } 75 \mathrm{mg} / \text { day on } \\
\text { day } 1-19, \text { day } 29-47\end{array}$ & NA & $33.1 \%$ (3-year) & $41.9 \%$ (3-year) & 62.0 \\
\hline Wang, 2013 & 65 & $70-72$ & $\begin{array}{l}\text { Cisplatin } 50 \mathrm{mg} / \mathrm{m}^{2} \text { on } \\
\text { day } 1 \text {, Tegafur } 800 \mathrm{mg} / \text { day }+\mathrm{LV} \\
60 \mathrm{mg} / \text { day on day } 1-14 \text {; every } 2 \text { weeks a } \\
\text { cycle, for four cycles }\end{array}$ & 70.7 & $50.6 \%$ (5-year) & $59.7 \%$ (5-year) & 80.0 \\
\hline
\end{tabular}

for patients treated between 2004 and 2010, the 5-year OS of stage III and IV oropharyngeal cancer was $43.1 \%$ and $30.8 \%$, respectively, and those of hypopharyngeal cancer was $36.7 \%$ and $22.5 \%$, respectively. ${ }^{[24]}$

Patients with SCCHN are at high risk of death resulting from noncancer causes and second primary cancer (i.e. competing mortality). ${ }^{[25,26]}$ In our study, second primary cancer developed in 14 of 46 post-CCRT complete responders and 1 of 9 post-CCRT/surgery complete responders. It accounts for $37 \%$ (10/27) of all-cause mortality. The high incidences of competing events degrade the efficiency of clinical studies. Risk stratification of patients for competing mortality may lead to more efficient and clinically appropriate designs for future study. ${ }^{[26]}$

Radiation-induced sensorineural hearing loss and CDDP-induced ototoxicity are well-known adverse events. Concurrent CDDP with radiotherapy resulted in comparatively worse sensorineural hearing than just radiotherapy alone. ${ }^{[27,28]}$ This risk did not seem to depend on cumulative doses of cisplatin, but on the fractional dose used per cycle. ${ }^{[29]}$ According to a report by Zuur, ${ }^{[30]}$ grade 3 hearing impairment (CTCAEv3.0) was 5\% in low-dose cisplatin (6 mg/m²/day for $20-25$ days) and $32 \%$ in high-dose cisplatin $\left(100 \mathrm{mg} / \mathrm{m}^{2}\right.$ for three infusions). In a prospective study by Hitchcock, ${ }^{[29]}$ patients who received high-dose cisplatin also had more risk of hearing loss than those who received a low dose. In our study, the hearing impairment rate among the survivors was $7.8 \%$. The lower cisplatin dose might translate to lower incidence of hearing impairment.

Byfield demonstrated that the sensitizing effects of 5-FU in vitro are maximal when exposure to 5-FU occurs for at least $24 \mathrm{~h}$ and up to $48 \mathrm{~h}$ after radiation exposure. ${ }^{[12]}$ This supports the continuous infusion approach (i.e., $1000 \mathrm{mg} / \mathrm{m}^{2} /$ day for 5 days) when given with fractionated irradiation. ${ }^{[31,32]}$ Tegafur, UFT (tegafur + uracil), S-1 (tegafur + gimeracil + oxonic acid), and capecitabine are the currently available oral 5-FU prodrugs. ${ }^{[33]}$ They all have radiosensitization and different toxicity profiles. Table 5 lists the phase II trial of CCRT using platinum and oral 5-FU for SCCHN. ${ }^{[21-23]}$ PTL has comparable effects to the other oral 5-FU regimens. Eighty percent of our patients experienced grade 3-4 mucositis, and they suffered from severe toxicity for only about $35 \%$ of the CCRT duration. The higher incidence of severe mucositis in our patients may be due to betel quid chewing-related chronic mucosa damage. ${ }^{[18]}$ Though there was a higher incidence of grade 3-4 mucositis, only five patients received RT dose $<6000 \mathrm{~Gy}$. The median administered CDDP dose was $75 \%$ of the scheduled dosage and that of tegafur was $77.5 \%$. The compliance was not different from that reported in the other oral 5-FU trials.

\section{Conclusion}

CCRT is the standard treatment for SCCHN, when organ preservation is desired or for unresectable diseases. During 2002-2005, 65 patients with advanced stage III or IV SCCHN in our hospital received CCRT with PTL regimen. After 5 years of follow-up, these patients had comparable LRC and OS, with good functional preservation rates. PTL could be one option of CCRT for SCCHN. However, further studies are still necessary to confirm the benefit.

\section{REFERENCES}

1. Forastiere AA, Goepfert H, Maor M, Pajak TF, Weber R, Morrison $\mathrm{W}$, et al. Concurrent chemotherapy and radiotherapy for organ preservation in advanced laryngeal cancer. N Engl J Med 2003;349:2091-8.

2. Adelstein DJ, Li Y, Adams GL, Wagner H Jr., Kish JA, Ensley JF, et al. An intergroup phase III comparison of standard radiation therapy and two schedules of concurrent chemoradiotherapy in patients with unresectable squamous cell head and neck cancer. J Clin Oncol 2003;21:92-8. 
3. Bernier J, Domenge C, Ozsahin M, Matuszewska K, Lefebvre JL, Greiner RH, et al. Postoperative irradiation with or without concomitant chemotherapy for locally advanced head and neck cancer. N Engl J Med 2004;350:1945-52.

4. Cooper JS, Pajak TF, Forastiere AA, Jacobs J, Campbell BH, Saxman SB, et al. Postoperative concurrent radiotherapy and chemotherapy for high-risk squamous-cell carcinoma of the head and neck. N Engl J Med 2004;350:1937-44.

5. Pignon JP, Bourhis J, Domenge C, Designe L. Chemotherapy added to locoregional treatment for head and neck squamous-cell carcinoma: Three meta-analyses of updated individual data. MACH-NC Collaborative Group. Meta-analysis of chemotherapy on head and neck cancer. Lancet 2000;355:949-55.

6. El-Sayed S, Nelson N. Adjuvant and adjunctive chemotherapy in the management of squamous cell carcinoma of the head and neck region. A meta-analysis of prospective and randomized trials. J Clin Oncol 1996;14:838-47.

7. Adelstein DJ, Saxton JP, Lavertu P, Tuason L, Wood BG, Wanamaker JR, et al. A phase III randomized trial comparing concurrent chemotherapy and radiotherapy with radiotherapy alone in resectable stage III and IV squamous cell head and neck cancer: Preliminary results. Head Neck 1997;19:567-75.

8. Brizel DM, Albers ME, Fisher SR, Scher RL, Richtsmeier WJ, Hars V, et al. Hyperfractionated irradiation with or without concurrent chemotherapy for locally advanced head and neck cancer. N Engl J Med 1998;338:1798-804

9. Merlano M, Benasso M, Corvo R, Rosso R, Vitale V, Blengio F, et al Five-year update of a randomized trial of alternating radiotherapy and chemotherapy compared with radiotherapy alone in treatment of unresectable squamous cell carcinoma of the head and neck. J Natl Cancer Inst 1996;88:583-9.

10. Wendt TG, Grabenbauer GG, Rodel CM, Thiel HJ, Aydin H, Rohloff R, et al. Simultaneous radiochemotherapy versus radiotherapy alone in advanced head and neck cancer: A randomized multicenter study. J Clin Oncol 1998;16:1318-24.

11. Vietti J, Eggerding F, Valeriote F. Combined X-radiation and 5-fluorouracil in survival of transplanted leukemic cells. J Natl Cancer Inst 1971;47:865-70.

12. Byfield JE, Calabro-Jones P, Klisak I, Kulhanian F. Pharmacologic requirements for obtaining sensitization of human tumor cells in vitro to combined 5-Fluorouracil or ftorafur and X rays. Int J Radiat Oncol Biol Phys 1982;8:1923-33.

13. Smalley SR, Kimler BF, Evans RG. 5-Fluorouracil modulation of radiosensitivity in cultured human carcinoma cells. Int J Radiat Oncol Biol Phys 1991;20:207-11.

14. Wang HM, Wang CH, Chen JS, Chang HK, Kiu MC, Liaw CC, et al. Cisplatin and 5-fluorouracil as neoadjuvant chemotherapy: Predicting response in head and neck squamous cell cancer. J Formos Med Assoc 1995;94:87-94.

15. Wang HM, Wang CH, Chen JS, Su CL, Liao CT, Chen IH. Impact of oral submucous fibrosis on chemotherapy-induced mucositis for head and neck cancer in a geographic area in which betel quid chewing is prevalent. Am J Clin Oncol 1999;22:485-8.

16. Wang HM, Hsueh CT, Wang CS, Chen IH, Liao CT, Tsai MH, et al. Phase II trial of cisplatin, tegafur plus uracil and leucovorin as neoadjuvant chemotherapy in patients with squamous cell carcinoma of the oropharynx and hypopharynx. Anti-Cancer Drugs $2005 ; 16: 447-53$
17. Wang HM, Wang CS, Chen JS, Chen IH, Liao CT, Chang TC. Cisplatin, tegafur, and leucovorin: A moderately effective and minimally toxic outpatient neoadjuvant chemotherapy for locally advanced squamous cell carcinoma of the head and neck. Cancer 2002;94:2989-95.

18. Pignon JP, Le Maitre A, Maillard E, Bourhis J; MACH-NC Collaborative Group. Meta-analysis of chemotherapy in head and neck cancer (MACH-NC): An update on 93 randomised trials and 17,346 patients. Radiother Oncol 2009;92:4-14.

19. Adelstein DJ, Lavertu P, Saxton JP, Secic M, Wood BG, Wanamaker JR, et al. Mature results of a phase III randomized trial comparing concurrent chemoradiotherapy with radiation therapy alone in patients with stage III and IV squamous cell carcinoma of the head and neck. Cancer 2000;88:876-83.

20. Denis F, Garaud P, Bardet E, Alfonsi M, Sire C, Germain T, et al. Final results of the 94-01 French Head and Neck Oncology and Radiotherapy Group randomized trial comparing radiotherapy alone with concomitant radiochemotherapy in advanced-stage oropharynx carcinoma. J Clin Oncol 2004;22:69-76.

21. Segura Huerta A, Díaz-Beveridge R, Pérez-Fidalgo JA, Calderero Aragón V, Pastor Borgoñón M, Aparicio Urtasun J, et al. Carboplatin and tegafur-uracil concomitant with standard radiotherapy in the management of locally advanced head and neck cancer. Clin Trans Oncol 2005;7:23-8.

22. Kim JG, Sohn SK, Kim DH, Baek JH, Jeon SB, Chae YS, et al. Phase II study of concurrent chemoradiotherapy with capecitabine and cisplatin in patients with locally advanced squamous cell carcinoma of the head and neck. Br J Cancer 2005;93:1117-21.

23. Fesneau M, Pointreau Y, Chapet S, Martin L, Pommier P, Alfonsi M, et al. Concomitant chemoradiotherapy using carboplatin, tegafur-uracil and leucovorin for stage III and IV head-and-neck cancer: Results of GORTEC Phase II study. Int J Radiat Oncol Biol Phys 2010;76:154-63.

24. Five-year survival rate of head and neck cancer in Taiwan. Reports of Bureau of Health Promotion, Department of Health, R.O.C.(Taiwan), 2013

25. Chen MC, Huang WC, Chan CH, Chen PT, Lee KD. Impact of second primary esophageal or lung cancer on survival of patients with head and neck cancer. Oral Oncol 2010;46:249-54.

26. Rose BS, Jeong JH, Nath SK, Lu SM, Mell LK. Population-based study of competing mortality in head and neck cancer. J Clin Oncol 2011;29:3503-9.

27. Schell MJ, McHaney VA, Green AA, Kun LE, Hayes FA, Horowitz M, et al. Hearing loss in children and young adults receiving cisplatin with or without prior cranial irradiation. J Clin Oncol 1989;7:754-60.

28. Low WK, Toh ST, Wee J, Fook-Chong SM, Wang DY. Sensorineural hearing loss after radiotherapy and chemoradiotherapy: A single, blinded, randomized study. J Clin Oncol 2006;24:1904-9.

29. Hitchcock YJ, Tward JD, Szabo A, Bentz BG, Shrieve DC. Relative contributions of radiation and cisplatin-based chemotherapy to sensorineural hearing loss in head-and-neck cancer patients. Int J Radiat Oncol Biol Phys 2009;73:779-88.

30. Zuur CL, Simis YJ, Verkaik RS, Schornagel JH, Balm AJ, Dreschler WA, et al. Hearing loss due to concurrent daily low-dose cisplatin chemoradiation for locally advanced head and neck cancer. Radiother Oncol 2008;89:38-43.

31. Byfield JE. 5-Fluorouracil radiation sensitization--a brief review. Invest New Drugs 1989;7:111-6. 
32. Calabro-Jones PM, Byfield JE, Ward JF, Sharp TR. Time-dose relationships for 5-fluorouracil cytotoxicity against human epithelial cancer cells in vitro. Cancer Res 1982;42:4413-20.
33. Rich TA, Shepard RC, Mosley ST. Four decades of continuing innovation with fluorouracil: Current and future approaches to fluorouracil chemoradiation therapy. J Clin Oncol 2004;22:2214-32. 